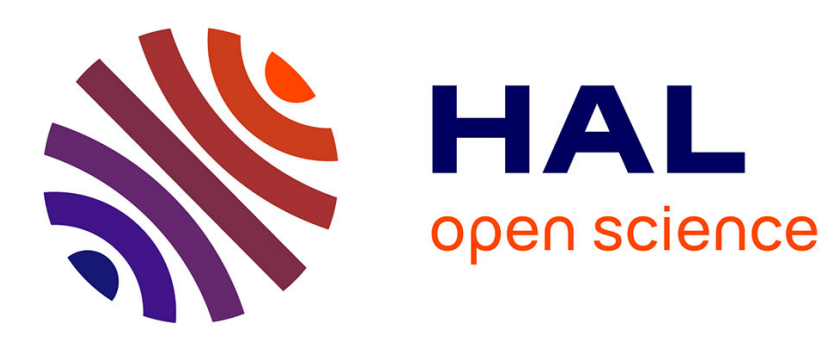

\title{
Detection of Liquid Water in PEM Fuel Cells' Channels: Design and Validation of a Microsensor.
}

\author{
Delphine Conteau, Caroline Bonnet, Denis Funfschilling, Mathieu Weber,
} Sophie Didierjean, François Lapicque

\section{- To cite this version:}

Delphine Conteau, Caroline Bonnet, Denis Funfschilling, Mathieu Weber, Sophie Didierjean, et al.. Detection of Liquid Water in PEM Fuel Cells' Channels: Design and Validation of a Microsensor.. Fuel Cells, 2010, 10 (4), pp.520. 10.1002/fuce.200900167 . hal-00552366

\section{HAL Id: hal-00552366 https://hal.science/hal-00552366}

Submitted on 6 Jan 2011

HAL is a multi-disciplinary open access archive for the deposit and dissemination of scientific research documents, whether they are published or not. The documents may come from teaching and research institutions in France or abroad, or from public or private research centers.
L'archive ouverte pluridisciplinaire HAL, est destinée au dépôt et à la diffusion de documents scientifiques de niveau recherche, publiés ou non, émanant des établissements d'enseignement et de recherche français ou étrangers, des laboratoires publics ou privés. 


\section{Detection of Liquid Water in PEM Fuel Cells' Channels: Design and Validation of a Microsensor.}

\begin{tabular}{|c|c|}
\hline Journal: & Fuel Cells \\
\hline Manuscript ID: & fuce.200900167.R1 \\
\hline Wiley - Manuscript type: & Original Research Paper \\
\hline $\begin{array}{r}\text { Date Submitted by the } \\
\text { Author: }\end{array}$ & 08-Jan-2010 \\
\hline Complete List of Authors: & $\begin{array}{l}\text { Conteau, Delphine; LEMTA } \\
\text { Bonnet, Caroline; LRGP } \\
\text { Funfschilling, Denis; LRGP } \\
\text { Weber, Mathieu; LRGP } \\
\text { Didierjean, Sophie; LEMTA } \\
\text { Lapicque, François; LRGP }\end{array}$ \\
\hline Keywords: & $\begin{array}{l}\text { Bipolar Plate, Gas Channels, Impedance Measurement, Liquid } \\
\text { Water, Microsensor, PEMFC }\end{array}$ \\
\hline
\end{tabular}

\section{ScholarONE \\ Manuscript Central}




\title{
Detection of Liquid Water in PEM Fuel Cells' Channels: Design and Validation of a Microsensor.
}

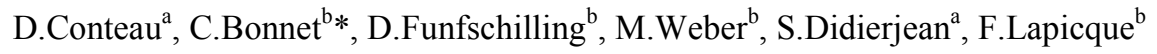 \\ ${ }^{a}$ Laboratoire d'Energétique et de Mécanique Théorique et Appliquée UMR 7563 CNRS, Nancy-University, 2 avenue \\ de la Forêt de Haye BP 160 \\ 54505 Vandoeuvre-lès-Nancy, France \\ ${ }^{\mathrm{b}}$ Laboratoire Réactions et Génie des Procédés UPR CNRS 3349 Nancy-University, CNRS, 1 rue Grandville B.P. 20451 \\ 54001 Nancy, France
}

[*] Corresponding author, caroline.bonnet@ensic.inpl-nancy.fr

\begin{abstract}
Suitable water management is a critical issue to reach the full potential of PEM fuel cells: whereas the membrane must be hydrated enough, liquid droplets formed by water in excess can block the flow in the gas distribution channels and hinder the fuel cell performance. In order to detect the presence of droplets in cathode flow channel, an electrochemical sensor has been developed and tested in a dedicated emulation cell. It is based on the widely used principle of twoelectrode cells for conductivity measurements; the collected signal is converted to impedance values. The sensor, mounted in a gas flow channel grooved in a graphite plate, reacts to the passage of water droplets, either being injected into the continuous air stream or produced by condensation of humidified air at the graphite plate. The time variation of the electrical impedance could be correlated to the observations allowed by the high-speed digital camera. Water droplets separated from each other by less than a second can be distinguished by the sensor, which is of a sufficient rapidity.
\end{abstract}

Keywords: Bipolar Plate, Gas channels, Impedance Measurement, Liquid water, Microsensor, PEMFC.

\section{Introduction}

Water management is one of the critical issues in the operation of proton exchange membrane fuel cells (PEMFCs). On one hand, the membrane must be sufficiently hydrated to allow the transport of protons from the anode side to the cathode side. But on the other hand, supersaturation of water vapour in the gas phase results in liquid water formation, which can be detrimental to the fuel cell operation. Liquid water can clog up the porous structure of the gas diffusion layer (GDL) and hinder the transport of gases in the catalyst layer. Liquid accumulation can also lead to the formation of water columns inside the gas flow channels, thus preventing the fuel gas from flowing into the reaction area, or inducing flow maldistribution, in parallel-channel configurations [1]. As direct consequences, the performance of the cell is reduced, and the overall pressure drop increases [2].

To avoid these drawbacks, various management strategies for water and gas flow have been developed. Nguyen and Knobbe [3] devised a method of sequentially exhausting each individual cell of a fuel cell stack. The point is to ensure that gas flows through the cells to ensure the required fuel supply, and also to evaporate the liquid water and remove it from the channels. The same goal was pursued by Li et al. [4], who developed a flow channel design procedure based on the determination of the appropriate pressure drop along the channel. Another idea consists in studying the effect of different flow field designs on flooding phenomenon [5,6], in order to select the best one, according to the working conditions considered.

The above investigations were conducted in the frame of fuel cell projects, which did not aim at understanding the physical phenomena linked to the presence of liquid water. Therefore, more and more studies have been focused on modelling water behaviour in the flow channels [7,8], and new diagnostic tools have been designed. The most largely used device seems to be the transparent fuel cell $[6,9,10]$ : bipolar plates are replaced by transparent plates, which allow water build up and flow to be observed with a digital camera. Flow channels can be grooved in the transparent plate [10] or formed by a thick current collector inserted between the GDL and the transparent plate [6]. This principle yields interesting flow observations, however not emulating real working conditions, particularly thermal conditions, due to the low thermal conductivity of the transparent materials used. Several imaging methods e.g. magnetic resonance imaging [11] or neutron imaging [12] have been also suggested and tested. However, these techniques involve a major disadvantage: the investigated cells must be machined out of specific materials, not to interfere with measurement devices.

The present study is focused on evidence of liquid water in view to be applied to real working fuel cells. A dedicated emulation cell was designed and constructed for this purpose. A home-made sensor was inserted in a channel, grooved in a graphite plate and closed by a transparent plate. The electrodes of this sensor were connected with an impedance converter and a microcomputer to measure the impedance of the fluid flowing in the channel. The experiments presented in this paper consist in injecting deionised water droplets in the gas flowing in the channel. Impedance 
measurement is analysed together with the frames of a digital camera for evaluation of the method. Further experiments have been conducted with water condensation, at the contact of the graphite plate, for the sake of better emulation of liquid formation in a PEMFC under operation, and to validate the technique.

\section{Principle and Design of the Microsensor}

Electrochemical methods have already been used for decades to measure the turbulence characteristics of gas-liquid flows, or to determine the velocity and the nature of the flowing phase present [13]. These methods are based on conductance measurements, or simultaneous measurements of conductivity and current. Recently, Lee et al. [14] developed an "impedance-void meter". This new device converts measured impedance signals to area-average void fractions to identify flow regimes in vertical two-phase flows.

For the measurement of electrical conductivity of liquids, two-electrode electrochemical cells are widely used in laboratories and they are still the subject of investigations [15]. Their principle is based on the simple law (1) relating the measured conductivity $\gamma$ to the ohmic conductance of the solution $G$.

$\gamma=\frac{d}{A} . G$

where $d$ is the distance between the two facing flat electrodes and $A$ is the electrode surface. $G$ is the reciprocal of the ohmic resistance, or impedance, when the system is supplied with alternating current.

Considering these available techniques, the idea came up to recreate a two-electrode electrochemical cell to be inserted in PEMFC flow channels.

\subsection{Measurement Principle}

As shown by Figure 1, two thin electrodes are mounted on each side of a bipolar plate channel. They are small enough not to come in contact with the GDL, on top of the channel edges. Connected with a data acquisition chain, they enable the measurement of the impedance of the flowing medium, being humid air or two-phase medium. This system does not aim at determining the accurate value of the medium conductivity, but at indicating doubtlessly whether the fluid passing through is in liquid or gaseous state.

\subsection{Description of the Impedance Converter}

The impedance converter, an AD5933 device (Analog Devices), is the key component of the measurement chain: it consists of a frequency generator using the Direct Digital Synthesis (DDS) technique, combined with a Digital Signal Processing engine (DSP).

The DDS core provides an excitation signal, whose frequency is determined by an internal clock. The transmission stage consists in a Digital-to-Analog Converter (DAC), which supplies the first electrode with alternating voltage. The current is transmitted, through the fluid within the channel (gas or liquid), to the second electrode, which conveys it to the receive stage. A current-to-voltage amplifier is required to work in the range of the following Analog-to-Digital Converter (ADC). Arising data are then ready to be processed by the DSP core, which performs a Discrete Fourier Transform (DFT) according to algorithm (2).

$$
X(f)=\sum_{n=0}^{N-1} x(n) \exp \left(j 2 \pi f \frac{n}{N}\right)
$$

where $X(f)$ is the power in the delivered voltage at the frequency $f ; x(n)$ is the ADC output. $N$ is equal to 1024 and is the number of samples needed for each measurement. The result $X(f)$ is stored in two 16-bit registers, representing its real $(R)$ and imaginary $(I)$ components.

The measured impedance is then equal to the reciprocal of the DFT magnitude, multiplied by a gain factor automatically estimated during the calibration stage. The phase of the measured impedance can also be calculated. In fact, the impedance range considered here is $0-560 \mathrm{k} \Omega$, corresponding to the calibration resistance. In addition, the excitation frequency is set at $5 \mathrm{kHz}$, even if it can limit the overall rate of the measurement procedure. For such a "low" frequency connection wires do not interfere with the recorded signals. According to the technical specifications of the converter [16], the impedance error in the present application impedance (100k $\Omega$ to $1 \mathrm{M} \Omega)$ and frequency ranges $(<10 \mathrm{kHz})$ does not exceed $0.5 \%$.

\subsection{Data Acquisition}

Printed circuit board was employed to manufacture the electrodes, because it is made of insulating polymer coated with a thin copper layer $(70 \mu \mathrm{m})$, so that they are perfectly electrically insulated from the bipolar plate. Very small pieces were cut $(9 \mathrm{~mm} \times 12 \mathrm{~mm}$ ) and adjusted to a $9 \mathrm{~mm}$ long milling. Narrow strips of copper ( $2 \mathrm{~mm})$ were removed along each side, and also $0.3 \mathrm{~mm}$ at the top, to guarantee electrical insulation from the GDL (Figure 2). Non-conductive resin had to be inserted between both electrodes, to prevent them from short circuit.

The three parts were first fastened together for easier handling, and secure introduction into a bipolar plate (Figure 3). The electrodes are connected with the AD5933 component, linked to the microcomputer connected to a PC via an USB interface. The measurement system is operated by means of a specifically developed Testpoint interface, which includes a start/stop button, calibration and gain factor calculation, selection of the excitation frequency and of the time step 


\begin{abstract}
between two points, with possible display of the phase variation along time. The impedance variation is visualised on-
\end{abstract} line and the corresponding data are stored in a file. The acquisition frequency can vary between 2 and $50 \mathrm{~Hz}$.

\title{
3 Water Injection Experiments \\ 3.1 Materials and Method
}

To test the ability of the sensor to detect the presence of liquid water, one prototype was manufactured as described in the previous paragraph (Figure 2). One graphite plate, shown in Figure 3, was especially designed. One serpentine channel, 3 times $50 \mathrm{~mm}$ long, $0.7 \mathrm{~mm}$ wide and $0.7 \mathrm{~mm}$ deep, was grooved in this graphite plate. The sensor was inserted in the middle of the second part of the channel. These channel dimensions are representative of currently investigated fuel cells [18]. The zoom on the inserted sensor (Figure 3) shows that it perfectly recreates a channel section, with one electrode along each side, and the bottom part formed by the insulating resin. The mechanical adjustment of the sensor in the channel is a critical point, because the gaseous or two-phase flow must not be disrupted by the sensor through the channel.

This home-made assembly was placed in the set-up presented in Figure 4. It is sandwiched between two transparent plates. The rear plate protects the graphite plates and the electrical wires from damage. The front plate has several functions: it closes the gas channel and allows the visualization of possible liquid flow. The system is placed vertically, to make easier the installation of the digital camera, which records frames of passing droplets. A microchannel for liquid injection was machined in the front plate, directly above the channel of the graphite plate (Figure 5). A septum, held by a shoulder in this channel, guarantees air tightness. A microsyringe is used to introduce water droplets into the air flow. A gasket was installed to ensure air and water tightness between the graphite and the transparent plate (Figures 4 and 5).

During fuel cell operation, water can condense if its saturated vapour pressure is reached. Then liquid water molecules in the fuel cell are either produced by the electrochemical reaction, or come from gas humidification, providing pure water. For this reason, deionised water is employed to simulate real working conditions. However, PEMFCs usually operate under acidic conditions ( $\mathrm{pH} 3-4)$, involving more conductive water. Thus, the use of deionised water is to be less favourable than water in a cell under operation. So the microsensors tested should be of higher sensitivity under real conditions.

Deionised water droplets are injected in a continuous dry air flow of $42 \mathrm{~mL} \mathrm{~min}{ }^{-1} \mathrm{STP}$ in the channel. According to Faraday's law, this flow rate should be applied in a fuel cell of $25 \mathrm{~cm}^{2}$ of active area fed by a single serpentine channel, with a stoichiometric ratio of 3 in air, producing a current of $1 \mathrm{~A}$. This flow rate is small in comparison to the actual air flow rates in $25 \mathrm{~cm}^{2}$ fuel cells under operation, but it was chosen for preliminary observation of water droplets. Tests with higher gas flow rates will be discussed later.

This system aims at recording simultaneously the impedance measured by the sensor and frames from the digital camera (Figure 4 right), a CamRecord 600 (Optronis). A comparison is made to gain understanding of the sensor response to a coming droplet, and to adjust measurement parameters e.g. excitation frequency or time step.

\subsection{Droplets Detection}

When only gas circulates in the channel grooved in the graphite plate, the impedance value is near $560 \mathrm{k} \Omega$, which corresponds to the calibration value for the impedance converter. But when the channel and the electrodes are already wet, as a consequence of previous experiments, the measured impedance is slightly lower than $560 \mathrm{k} \Omega$. That is the case of the typical impedance response presented in Figure 6. Regardless of the initial impedance, the occurrence of a water droplet flowing through the channel generates a significant, sudden impedance drop.

In Figure 6, the first droplet $(10 \mu \mathrm{L})$ is injected 4 seconds after the beginning of the recording. Impedance drops and rises back up very abruptly, which corresponds exactly to the presence of water inside the sensor, shown by the frames made thanks to the digital camera. The second $10 \mu \mathrm{L}$ water droplet is injected at $14 \mathrm{~s}$ and is split into two smaller droplets during its progress along the channel. Even though these two droplets remain very close, i.e. separated by less than one second, they generate two separate impedance peaks of high resolution, which demonstrates that "close" droplets can be distinguish by the developed system.

Impedance recording perfectly matches the observations made by the digital camera. Figure 7 left is the picture corresponding exactly to the triangle-shape mark in Figure 6. At that time, the droplet just arrives between the electrodes and the impedance is still high. Figure 7 right presents the same droplet occupying the whole space between electrodes. Corresponding measured impedance, indicated by the circle-shape mark in Figure 6, attains a minimum. These phenomena are so fast, that the time step has to be as low as $20 \mathrm{~ms}$ for possible detection. After a large number of injection tests, several general observations can be made, as follows:

- The impedance begins to fall exactly at the time when a water droplet arrives between the two electrodes to create an electrical contact, and comes back up when water flows out. There is obviously a relationship between the area of wet copper and impedance variation. For example, impedance minimums always correspond to total filling of the space between the electrodes. But the absolute values of the minimums differ from one drop to another, as shown in Figure 6, and no correlation could be established.

- In some cases, impedance remains low for a while. It results from two different phenomena. At equivalent speed, a larger droplet leads to a wider "impedance peak", because the volume between electrodes is filled 


\subsection{One Characteristic Parameter: the Residence Time}

To characterise the behaviour of the sensor, droplets of different volumes were injected into the set-up (Figure 4). In order to vary the velocity of injected droplets, the air flow rate is modified. As already mentioned before, its value was first $42 \mathrm{~mL} \mathrm{~min}^{-1} \mathrm{STP}$, and tests showed that:

- below $25 \mathrm{~mL} \mathrm{~min}^{-1} \mathrm{STP}$, droplets did not move;

- above $70 \mathrm{~mL} \mathrm{~min}^{-1} \mathrm{STP}$, droplets were sprayed into microdroplets, which did not clog the channel any more. Finally, the three air flow rates used for the experiments were 32,42 and $52 \mathrm{~mL} \mathrm{~min}^{-1} \mathrm{STP}$. Since the microsyringe is calibrated, the volumes of the injected droplets can be precisely known: $6 \mu \mathrm{L}, 8 \mu \mathrm{L}$ and $10 \mu \mathrm{L}$. Each (air flow rate droplet volume) couple was tested five times, to reduce inaccuracies due to the very small amounts of water handled, and to collect enough data for a pertinent analysis.

The films, realised with the digital camera, gave useful information for the sensor study. First of all, they allowed calculation of the real volume of the droplets passing through the sensor, which may differ from the amount of water injected. In fact, the gasket around the channel does not completely seal the set-up, and a fraction of injected water then flows between the graphite plate and the transparent plate. Another fraction of water can flow as a thin film along the sidewalls of the channel and is not clearly visible in frames. Therefore, it was important to determine the real amount of water corresponding to recorded impedance peaks.

A program was developed to record the time when the leading edge and the trailing edge of the droplet pass through the sensor inlet and through the sensor outlet (see Figure 8). Since the distance between the sensor inlet and outlet equals $9 \mathrm{~mm}$, the velocity of the leading edge and of the trailing edge inside the sensor can be calculated indirectly. In most cases, the leading edge of the droplet is faster than its trailing edge. Several explanations can be given. First, the insulating resin layer could slightly hinder the droplets motion because of its roughness. Besides, the thin film of water, flowing upstream from the sensor, can merge with the droplet at this point, thus increasing the residence time of the trailing edge.

The purpose of the experiments is to compare the information given by the impedance measurements with information inferred thanks to corresponding frames. The residence time can be easily deduced from these two different data sources. In impedance curves, the peak width $T_{\text {peak }}$ can be defined as the time difference between the onset of impedance decay and its further increase back to the initial level. These characteristic points correspond respectively to the entrance of the leading edge of the droplet into the sensor and to the exit of the trailing edge. In the meantime, the droplet flows over the distance $L$, which equals its own length plus the sensor length:

$L=L_{\text {sensor }}+L_{\text {droplet }}$

Considering $u$ the velocity of the droplet in the sensor area - calculated indirectly by the program, the residence time $\tau$ can be defined as:

$\tau=\frac{L}{u}$

As already explained in the previous paragraph, the leading edge and the trailing edge of the droplet do not have the same velocity. Therefore, two different residence times can be calculated:

$\tau_{\text {lead. }}=\frac{L}{u_{\text {leading edge }}}$ and $\tau_{\text {trail. }}=\frac{L}{u_{\text {trailing edge }}} \quad$ (5) and (6)

The average residence time was used for data interpretation:

$\tau_{a v}=\frac{1}{2}\left(\frac{L}{u_{\text {leading edge }}}+\frac{L}{u_{\text {trailing edge }}}\right)$

The peak width $T_{\text {peak }}$ is compared to the average residence time $\tau_{a v}$ in Figure 9, for all the experiments with the three different air flow rates. Figure 9 shows the linear relationship between the two characteristic times, with a regression coefficient near 0.94 . However, the slope of the linear law is higher than 1 . This can be explained by the likely underestimation of the volume of droplets. The droplets volumes were measured on the frames taken with the digital camera. The main difficulty of this method is related to the droplet meniscus due to capillary action at the channel walls. This possible explanation can be confirmed by the simultaneous observation of a droplet flowing through the sensor and of the corresponding variation of the impedance value. This observation is made possible by the film available on the website of LRGP (http://www.ensic.inpl-nancy.fr/LSGC/videos/injection.mpg). Figure 10 shows four characteristic frames of this film: 


\section{Condensation Experiments 4.1 The Method Used}

This new experiment consists in injecting humidified air to the emulation cell and making water vapour condense inside the channel, at the contact of the graphite plate, maintained at controlled temperature. The experimental set-up showed in Figure 4 was slightly modified. The transparent plate behind was replaced with a brass plate and a heating element fixed to it. By using a thermocouple inserted in the microchannel, the temperature of the grooved graphite plate could be monitored and controlled by the heating element. A heating ribbon, wrapped around the air supply pipe, prevent water from condensing between the humidifier used in previous investigations [17] and the cell inlet. In research projects carried out in the lab, $25 \mathrm{~cm}^{2}$ fuel cells are currently run at $64^{\circ} \mathrm{C}$, with a current density of $0.54 \mathrm{~A} \mathrm{~cm}^{-2}$ : the dry air flow rate is $672 \mathrm{~mL} \mathrm{~min}^{-1} \mathrm{STP}$, taking into account a stoichiometric coefficient of 3 for oxygen. Liquid water is collected at the anode and the cathode sides, with a total amount of $6 \mathrm{~g} \mathrm{~h}^{-1}$ on average, during these experiments in fuel cells. Water balance in the cell is usually calculated, together with the water diffusion ratio $\alpha$. This parameter is defined as the ratio of the flux of water produced by the electrochemical reaction and collected at the anode side, over the total flux of water produced. The maximum water flow rate at the cathode side corresponds to zero $\alpha$ value. For this reason, emulation experiments were designed with a water flow of $6 \mathrm{~g} \cdot \mathrm{h}^{-1}$ injected into dry air, by means of the humidifier. Taking into account the flow rates of water and dry air, the temperatures of the heated graphite plate and of the humidifier could be calculated:

$\theta_{\text {cell }}=35^{\circ} \mathrm{C}$

$\theta_{\text {hum }}=60^{\circ} \mathrm{C}$

Preliminary calculation showed that humidified air is cooled to the graphite plate temperature, within a fraction of a degree, a few centimetres after the channel inlet. As in Section 3, impedance was continuously recorded, and liquid flow filmed with the digital camera for possible validation of the technique.

\subsection{Validation of the Sensor}

Figure 11 gives a part of the impedance variation with time recorded during a condensation test, conducted for more than ten minutes. This graph shows that "close droplets" i.e. droplets of appreciable size and separated by less than two seconds, can be distinguished from each other. Besides, very small droplets generate peaks of very small amplitude. However, the peak widths are of the same order of magnitude as for injection tests, and usually range from 0.5 to $2 \mathrm{~s}$. For this reason, the previous characterisation of the sensor (Figure 9) is still valid and the sensor is to be capable of detecting the small and fast droplets formed in a real PEM fuel cell under operation.

Figure 12 shows two frames from a film of one condensation test and the corresponding impedance time variation. The entire film is also available on the website of LRGP (http://www.ensic.inpl-nancy.fr/LSGC/videos/condensation.mpg). At the beginning of the run, the impedance is lower than for other tests, because the channel walls were partly wet. Measurements are nevertheless not disturbed. Because higher air flow rate is injected here, droplets are dragged along the channel and do not form a slug. However the insulating resin inside the sensor is more wettable than graphite (as controlled by visual observations) and droplets can spread when they enter this section, creating an electrical contact between the electrodes and causing impedance peaks. Thus the droplets flow as a film inside the sensor and recover partly their initial shape as they flow away. This phenomenon generates impedance peaks of amplitude of the same order as the smallest peaks visible in Figure 11, proving that even "microdroplets" (with a volume of less than $1 \mu \mathrm{L}$, as calculated from frames) are detected among bigger droplets. Finally, each impedance peak corresponds to a water droplet and should be taken into account for data analysis. 


\section{Conclusion and Future Prospects}

All the experiments presented here aimed at demonstrating the feasibility of the method. The ability of the home-made microsensor to react to the passage of water droplets has been demonstrated in a specially designed set-up under different conditions.

The first injection tests were not representative of what happens in a fuel cell, because the air flow was dry, and the amount of water injected was much lower than the amount really produced. However, they were required as preliminary tests. The synchronisation of the films with the impedance measurements proved the ability of the sensor to detect water droplets of different volumes (6 to $10 \mu \mathrm{L}$ ). The study of impedance peaks width showed that this width interrelates the droplets residence time, and will be helpful to study working fuel cells. Nevertheless, residence time combines the velocity of the droplets with their length. The current system does not allow to calculate any of these fundamental parameters. One possibility to determine the velocity of droplets would be to insert two sensors, not far from each other, along the gas channel.

The condensation tests aimed at creating smaller and more frequent droplets, to get closer to real conditions. Impedance measurement were also validated by films, even if droplets spread into the sensor and become hardly visible on frames. Besides, some very interesting characteristics of the sensor were highlighted. First of all, the detection of very close droplets, with less than a second in-between, showed the rapidity of the system. Then, its sensitivity was proved by the use of deionised water to simulate fuel cell condensate, and by the detection of very small droplets of less than one microlitre. Finally, the fact that impedance always recovers its initial value indicates the electrical stability of the system.

The next step will consist in incorporating several sensors in a standard bipolar plate to be implemented in a real fuel cell. Several parameters, such as pressure drop and voltage of the cell, will be monitored simultaneously with the impedance measurement. This original method should enable a statistic study of water-forming in PEMFCs to gain understanding of the physical phenomenon and to determine:

- whether the formation of droplets occurs in a definite location at regular intervals;

- whether the droplets move along the channel at constant velocity;

- the relationship between the presence of liquid water at identified locations and the PEMFCs electrical performance. This method was developed for PEMFCs because of the significance of water management in such energy conversion systems. It could be applied to the study of other two-phase flows in different systems, in particular in sub-millimetric heat exchangers with phase change.

\section{Acknowledgement}

The authors would like to acknowledge the contribution of Pascal Beaurain in the design of the microsensor discussed here. All the technical team of ENSIC (Chemical Engineering School of Nancy) is also gratefully acknowledged for the making of the test pilot mounting.

The CARNOT-ICEEL group is also gratefully acknowledged for funding facilities.

This paper is based on preliminary results presented during the FDFC Conference held in Nancy, France in December 2008 .

\section{List of symbols}

\section{A Electrode surface $\left(\mathrm{m}^{2}\right)$}

d Distance between the two facing electrodes of a device for the measurement of liquid conductivity $(\mathrm{m})$

$\mathrm{G} \quad$ Ohmic conductance of a solution $\left(\mathrm{S}\right.$ or $\left.\Omega^{-1}\right)$

GDL Gas Diffusion Layer

$\mathrm{L} \quad$ Total distance covered by the droplet during $\mathrm{T}_{\text {peak }}(\mathrm{m})$

$\mathrm{L}_{\text {droplet }} \quad$ Length of the considered droplet (m)

$\mathrm{L}_{\text {sensor }} \quad$ Length of the sensor $\left(910^{-3} \mathrm{~m}\right)$

PEMFC Proton Exchange Membrane Fuel Cell

STP Standard Temperature and Pressure

$\mathrm{T}_{\text {peak }} \quad$ Width of the impedance peak (s)

$\mathrm{u}_{\text {leading edge }}$ Velocity of the leading edge of the droplet $\left(\mathrm{m} \mathrm{s}^{-1}\right)$

$u_{\text {trailing edge }}$ Velocity of the trailing edge of the droplet $\left(\mathrm{m} \mathrm{s}^{-1}\right)$

$\alpha \quad$ Water diffusion ration (-)

$\gamma \quad$ Conductivity of a solution $\left(\mathrm{S}\right.$ or $\left.\Omega^{-1}\right)$

$\theta_{\text {cell }} \quad$ Temperature of the emulation cell $\left({ }^{\circ} \mathrm{C}\right.$ or $\left.\mathrm{K}\right)$

$\theta_{\text {hum }} \quad$ Temperature of the gas humidifier $\left({ }^{\circ} \mathrm{C}\right.$ or $\left.\mathrm{K}\right)$

$\tau_{\mathrm{av}} \quad$ Average residence time of the droplet inside the sensor (s)

$\tau_{\text {lead }} \quad$ Residence time of the leading edge of the droplet inside the sensor (s)

$\tau_{\text {trail }} \quad$ Residence time of the trailing edge of the droplet inside the sensor (s) 


\section{References}

[1] S. Maharuddrayya, S. Jayanti, A.P. Deshpande, J. Power Sources 2006, 157, 358.

[2] X. Liu, H. Guo, F. Ye, C.F. Ma, Electrochim. Acta 2007, 52, 3607.

[3] T.V. Nguyen, M.W. Knobbe, J. Power Sources 2003, 114, 70.

[4] X. Li, I. Sabir, J. Park, J. Power Sources 2007, 163, 933.

[5] A. Su, F-B. Weng, C-Y. Hsu, Y-M. Chen, Int. J. Hydrogen Energ 2006, 31, 1031.

[6] X. Liu, H. Guo, C. Ma, J. Power Sources 2006, 156, 207.

[7] Z. Zhan, J. Xiao, M. Pan, R. Yuan, J. Power Sources 2006,160, 1.

[8] L. You, H. Liu, Int. J. Heat Mass Tran 2002, 45, 2277.

[9] K. Tüber, D. Pocza, C. Hebling, J. Power Sources 2003, 124, 403.

[10] G. Maranzana, O. Lottin, T. Colinart, S. Chupin, S. Didierjean, J. Power Sources 2008, 180, 748.

[11] J. Bedet, G. Maranzana, S. Leclerc, O. Lottin, C. Moyne, D. Stemmelen, P. Mutzenhardt, D. Canet, Int. J. Hydrogen Energ 2008, 33, 3146.

[12] R. Satija, D.L. Jacobson, M. Arif, S.A. Werner, J. Power Sources 2004, 129, 238.

[13] C.W. Snoek, Exp. Therm Fluid Sci. 1990, 3, 60.

[14] J.Y. Lee, M. Ishii, N.S. Kim, Int J. Heat Mass Tran 2008, 51, 3442.

[15] D. Ramirez Muñoz, S. Casans Berga, Measurement 2005, 38, 181.

[16] Data sheet of 1 MSPS, 12-Bit Impedance Converter AD5933, Analog Devices, Rev.A, 2008.

[17] M. Boillot, C. Bonnet, S. Didierjean, F. Lapicque, J. Appl. Electrochem 2007, 37, 103.

[18] M. Boillot, S. Didierjean, F. Lapicque, Chem. Eng. Sci. 2005, 60, 1187.

[19] D. Conteau, C. Bonnet, D. Funfschilling, M. Weber, S. Didierjean, F. Lapicque, Proc. Fundamentals and Developments of Fuel Cells 2008 Conference, Nancy, France, 2008, pp.124. 


\section{Figure Caption}

Fig. 1 Principle of the sensor inserted in a flow channel.

Fig. 2 Manufacture of the microsensor.

Fig. 3 Specially grooved graphite plate and zoom on the inserted sensor.

Fig. 4 Pilot set-up to test the impedance measuring system (left: global view; right: zoom on the mounted sensor with the digital camera). (A) air inlet, (B) air outlet, (C) microchannel for water droplets injection, (D) gasket, (E) connection wires between the home-made sensor and impedance converter.

Fig. 5 Sectional scheme of the microchannel machined for water injection.

Fig. 6 Typical impedance response to passing water droplets.

Fig. 7 Pictures made with the digital camera (left: droplet entering the system at $17.58 \mathrm{~s}$; right: droplet taking up the whole space between electrodes at $17.83 \mathrm{~s}$ )

Fig. 8 Definition of characteristic locations. View of a droplet, highlighted in blue, inside the sensor.

Fig. 9 Comparison of peaks' width values with corresponding average residence times.

Fig. 10 Four pictures of a passing droplet and corresponding impedance measurements: gas and liquid flow to the left (air flow rate: $42 \mathrm{~mL} \min ^{-1} \mathrm{STP}$; droplet volume: $3 \mu \mathrm{L}$ ).

Fig. 11 Part of the time impedance variation recorded during the 10-min. condensation test. (air flow rate: $672 \mathrm{~mL} \mathrm{~min}^{-}$ ${ }^{1} \mathrm{STP}$; water flow rate: $6 \mathrm{~g} \mathrm{~h}^{-1} ; \mathrm{T}_{\text {cell }}=35^{\circ} \mathrm{C} ; \mathrm{T}_{\text {humidification }}=60^{\circ} \mathrm{C}$ ).

Fig. 12 Pictures of condensation droplets and corresponding impedance measurements. (Same operating conditions as for fig. 11) 
Humid air (potentially with liquid water)

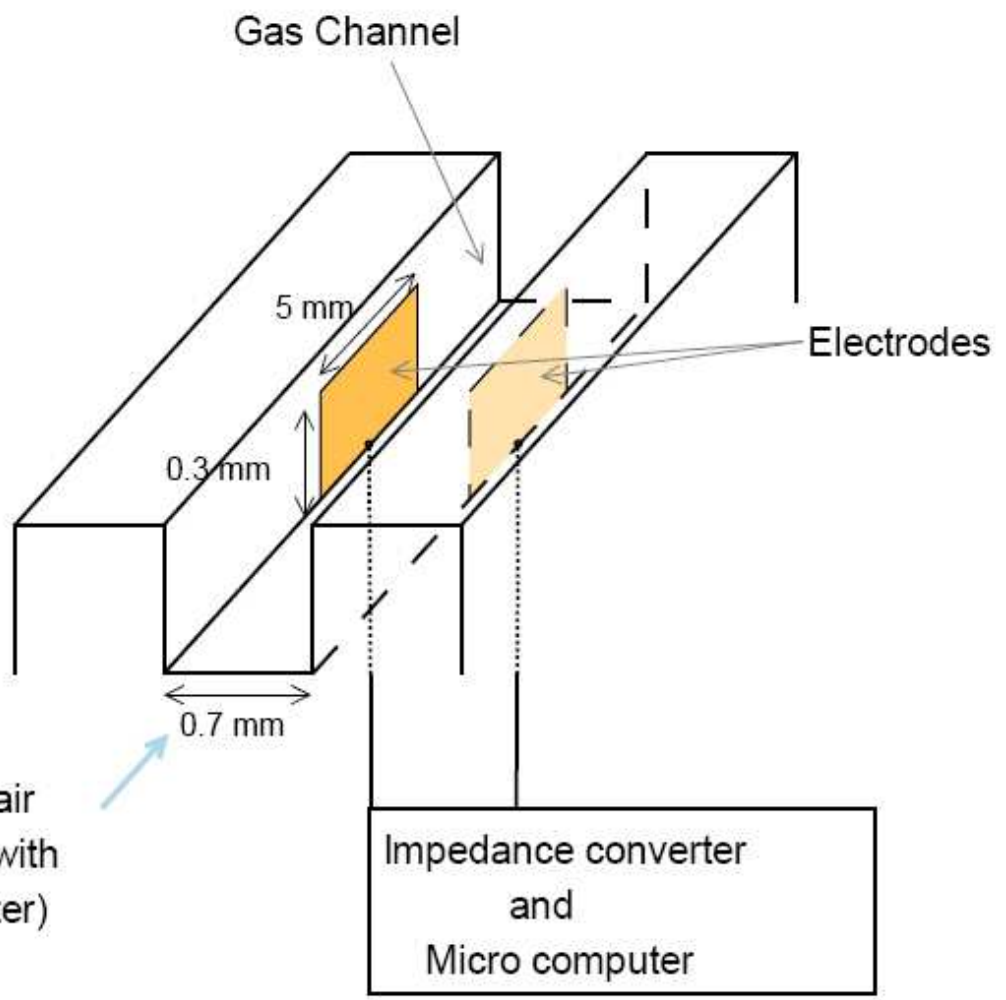

Fig. 1 Principle of the sensor inserted in a flow channel. $175 \times 140 \mathrm{~mm}$ ( $96 \times 96$ DPI) 


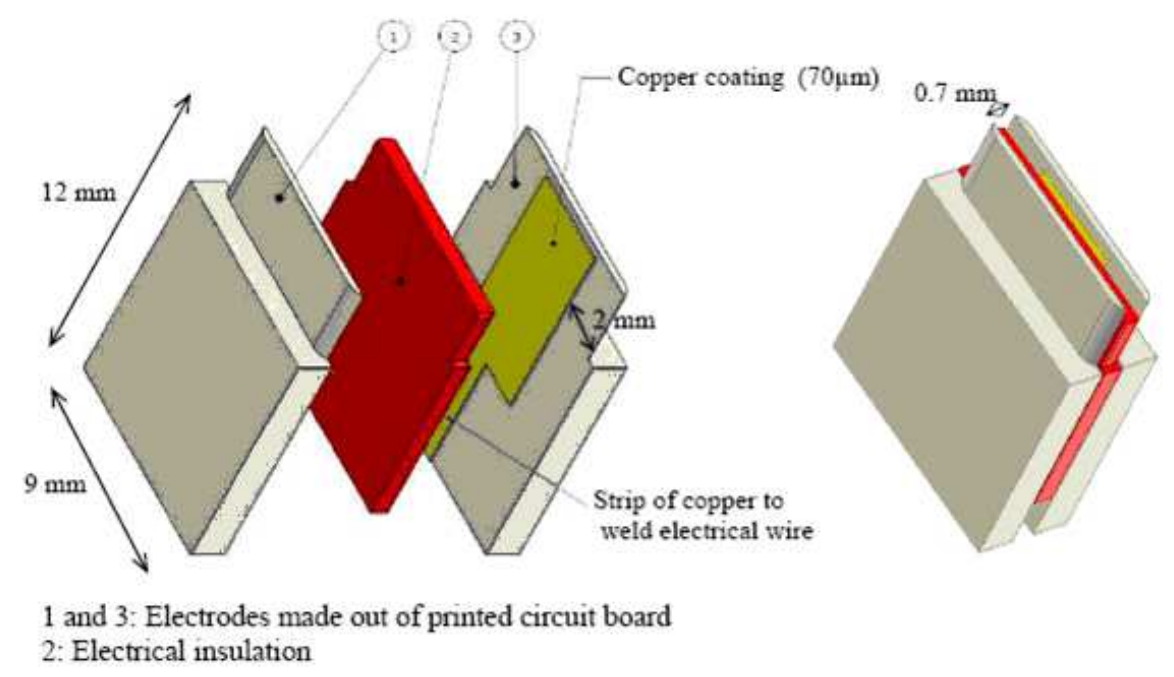

Fig. 2 Manufacture of the microsensor. $169 \times 105 \mathrm{~mm}(96 \times 96 \mathrm{DPI})$ 
Fig. 3 Specially grooved graphite plate and zoom on the inserted sensor. $177 \times 105 \mathrm{~mm}(96 \times 96 \mathrm{DPI})$ 
Fig. 4 Pilot set-up to test the impedance measuring system (left: global view; right: zoom on the mounted sensor with the digital camera). (A) air inlet, (B) air outlet, (C) microchannel for water droplets injection, (D) gasket, $(E)$ connection wires between the home-made sensor and impedance converter. 


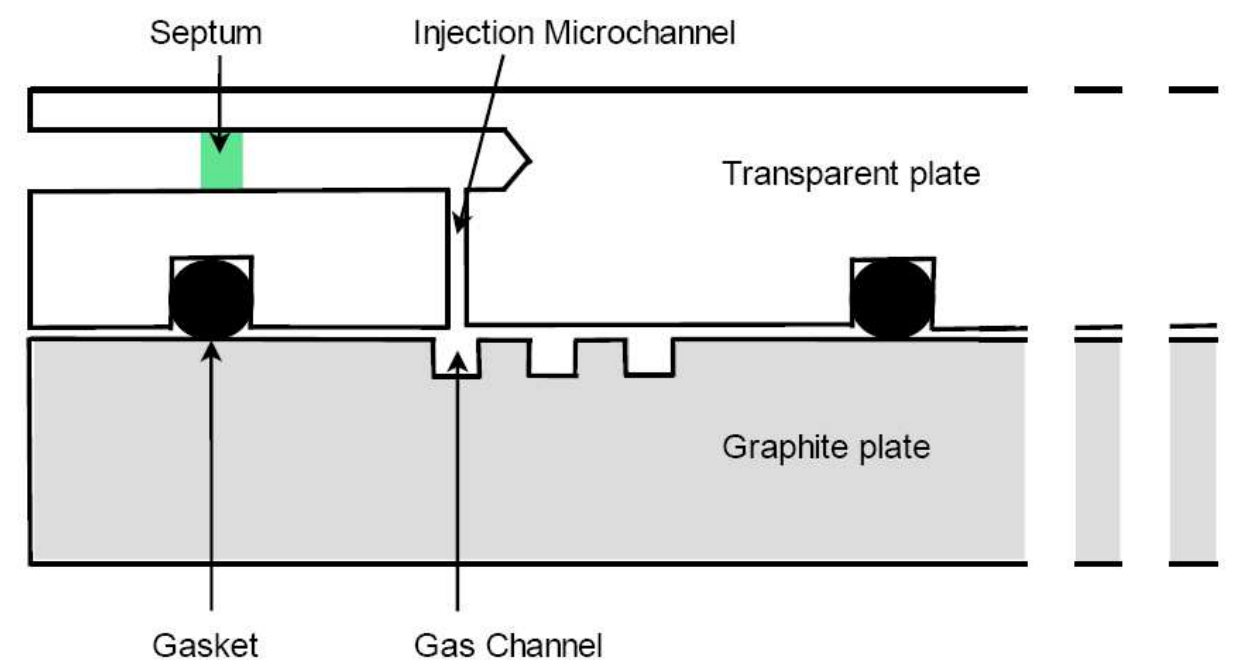

Fig. 5 Sectional scheme of the microchannel machined for water injection. $243 \times 142 \mathrm{~mm}(96 \times 96 \mathrm{DPI})$ 


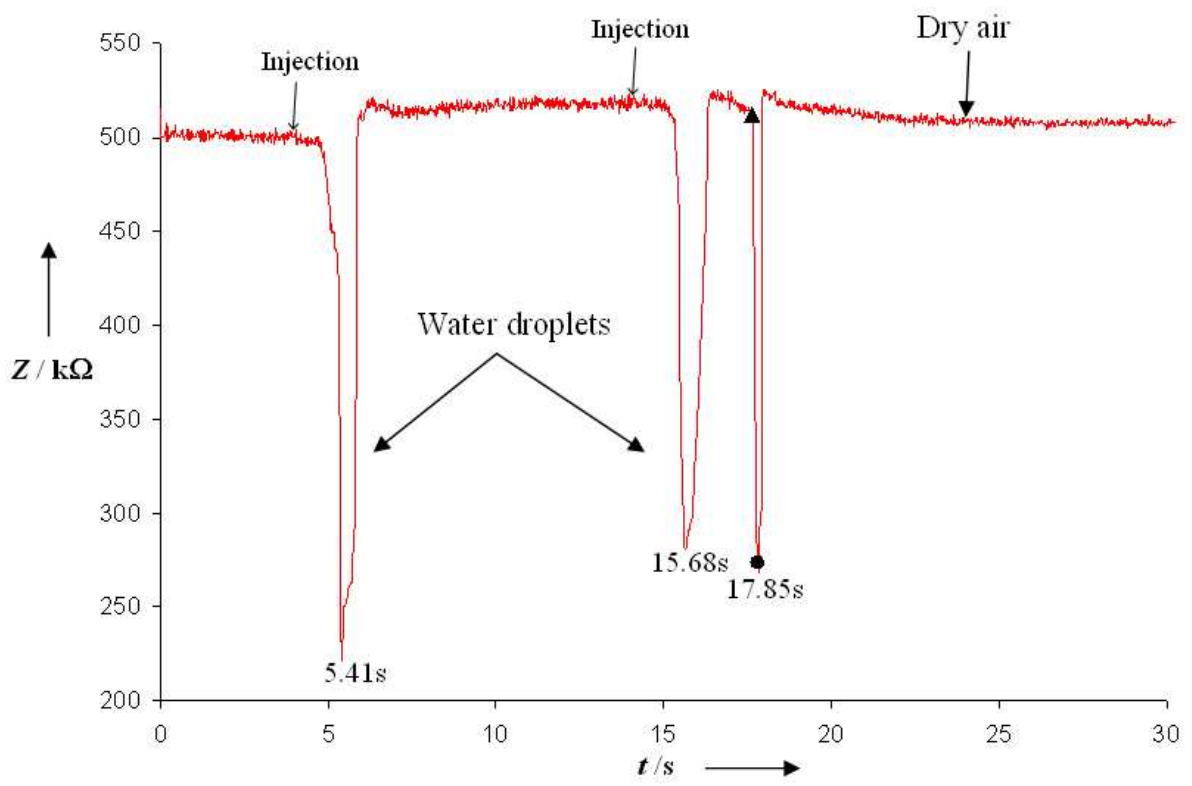

Fig. 6 Typical impedance response to passing water droplets. $233 \times 142 \mathrm{~mm}(96 \times 96 \mathrm{DPI})$ 
Fig. 7 Pictures made with the digital camera (left: droplet entering the system at $17.58 \mathrm{~s}$; right: droplet taking up the whole space between electrodes at $17.83 \mathrm{~s}$ ) $261 \times 105 \mathrm{~mm}(96 \times 96 \mathrm{DPI})$ 
Fig. 8 Definition of characteristic locations. View of a droplet, highlighted in blue, inside the sensor. $244 \times 105 \mathrm{~mm}$ (96 x 96 DPI) 
1

2

3

4

5

6

7

8

9

10

11

12

13

14

15

16

17

18

19

20

21

22

23

24

25

26

27

28

29

30

31

32

33

34

35

36

37

38

39

40

41

42

43

44

45

46

47

48

49

50

51

52

53

54

55

56

57

58

59

60

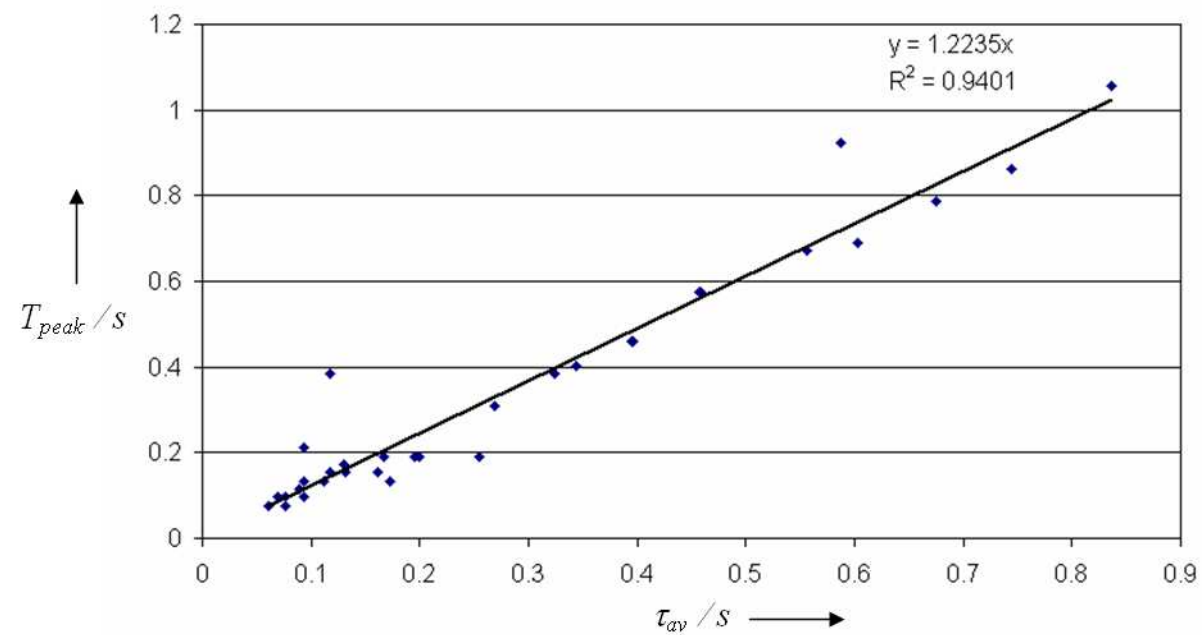

Fig. 9 Comparison of peaks' width values with corresponding average residence times. $268 \times 139 \mathrm{~mm}(96 \times 96 \mathrm{DPI})$ 

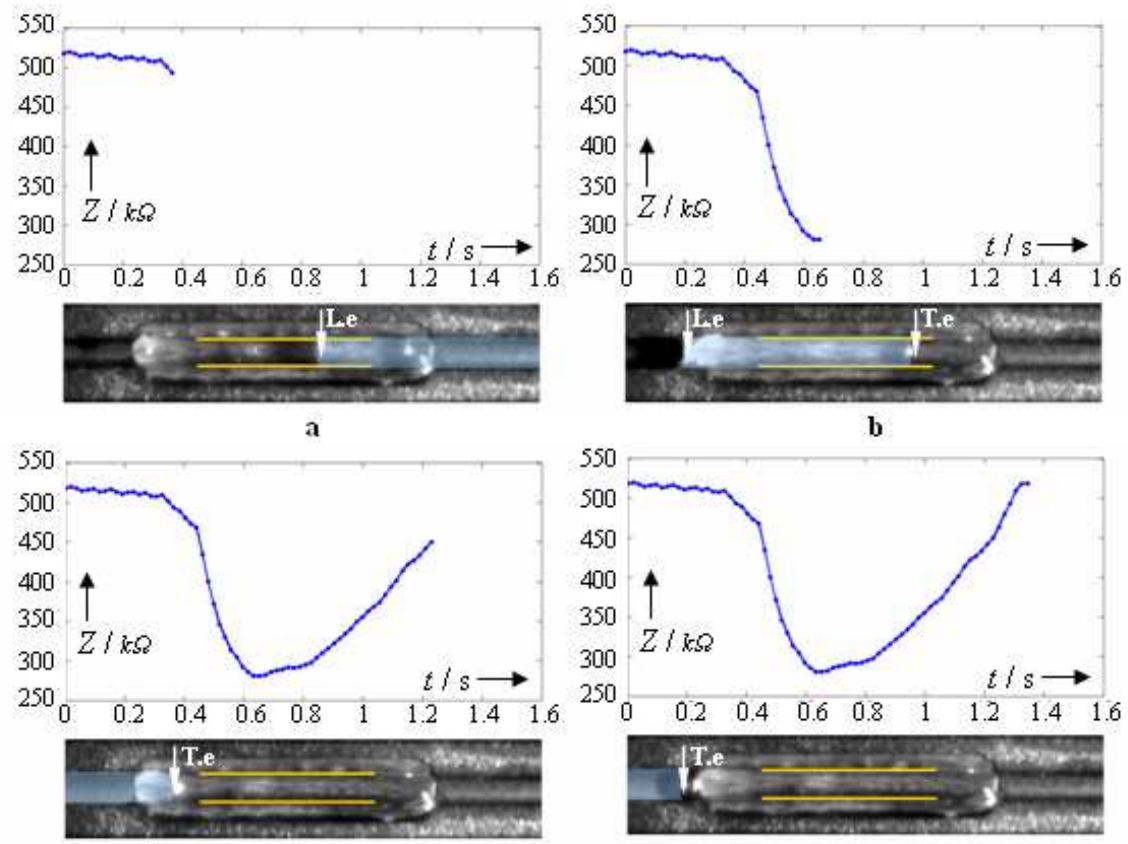

c

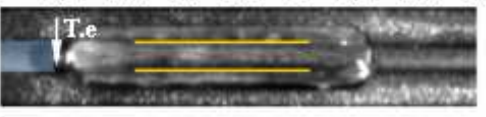

d

L.e $=$ Leading edge $\quad$ T.e $=$ Trailing edge

Fig. 10 Four pictures of a passing droplet and corresponding impedance measurements: gas and liquid flow to the left (air flow rate: $42 \mathrm{~mL}$ min-1 STP; droplet volume: $3 \mu \mathrm{L}$ ). $169 \times 125 \mathrm{~mm}(96 \times 96 \mathrm{DPI})$ 
1

2

3

4

5

6

7

8

9

10

11

12

13

14

15

16

17

18

19

20

21

22

23

24

25

26

27

28

29

30

31

32

33

34

35

36

37

38

39

40

41

42

43

44

45

46

47

48

49

50

51

52

53

54

55

56

57

58

59

60

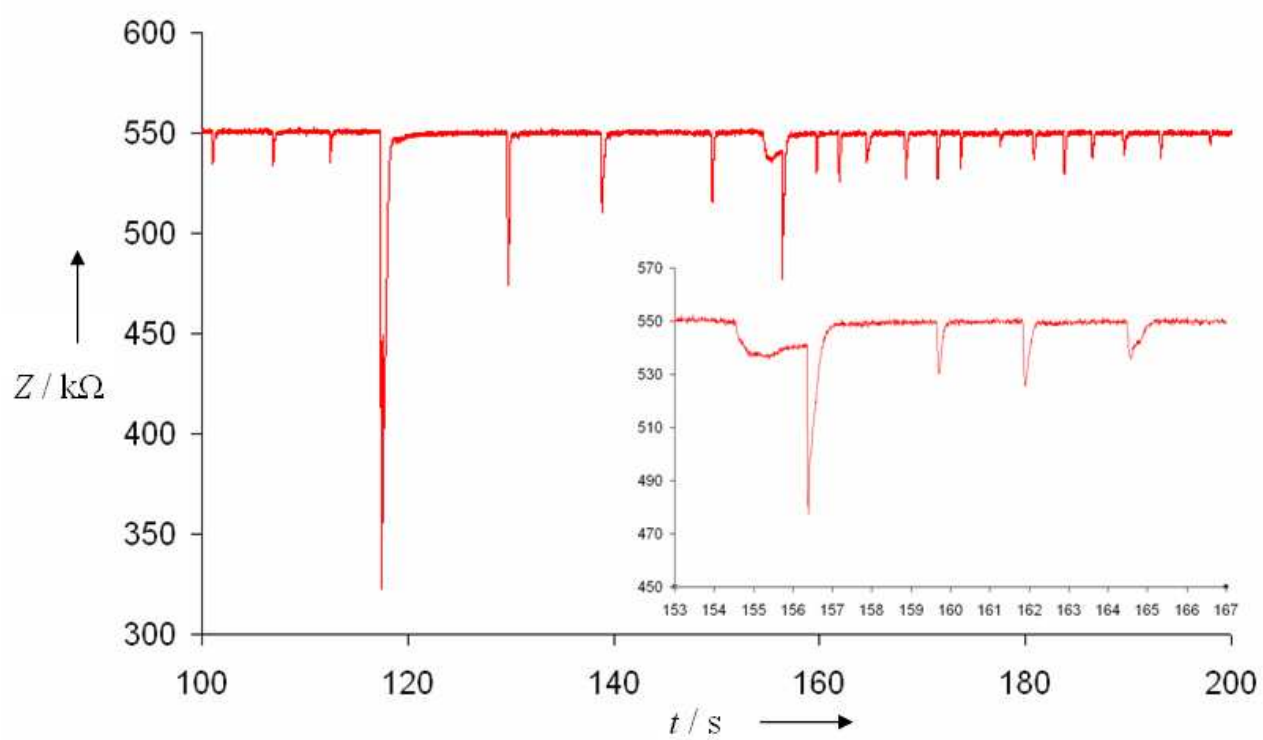

Fig. 11 Part of the time impedance variation recorded during the 10 -min. condensation test. (air flow rate: $672 \mathrm{~mL}$ min-1 STP; water flow rate: $6 \mathrm{~g} \mathrm{~h}-1$; Tcell $=35^{\circ} \mathrm{C}$; Thumidification $=60^{\circ} \mathrm{C}$ ). $218 \times 130 \mathrm{~mm}(96 \times 96 \mathrm{DPI})$ 

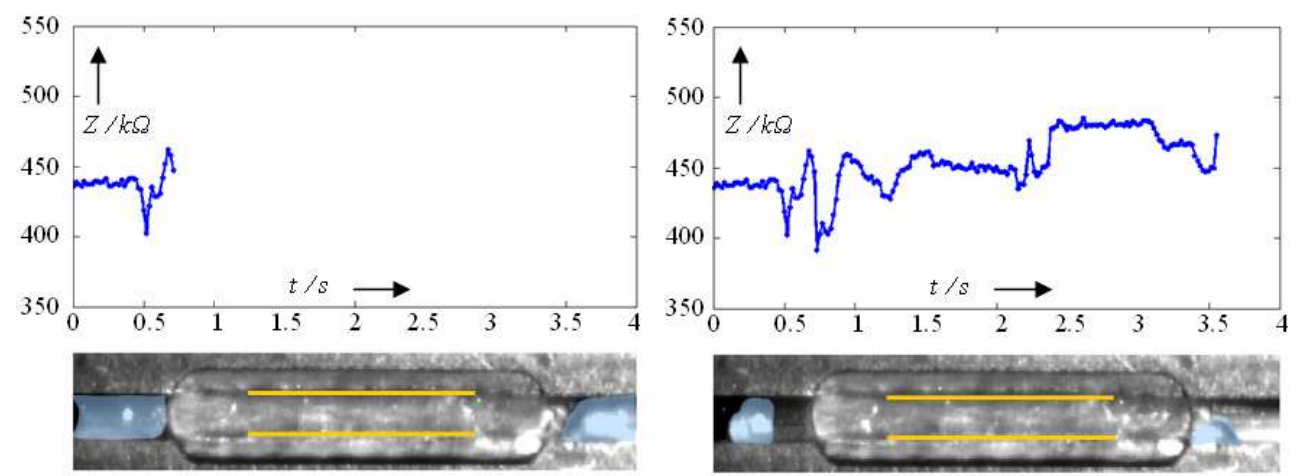

Fig. 12 Pictures of condensation droplets and corresponding impedance measurements. (Same operating conditions as for fig.11) $238 \times 105 \mathrm{~mm}$ (96 x 96 DPI) 